\title{
Gamification Technique in Engineering Education to Improve Learnability
}

\author{
N. Ravinder Reddy ${ }^{1}$, V.V. Satyanarayana ${ }^{2}$, J. Jagadesh Kumar ${ }^{1}$, G. Sreeram Reddy ${ }^{2}$ \\ ${ }^{1}$ Associate Professor, Vidya Jyothi Institute of Technology, Aziznagar, Hyderabad \\ ${ }^{2}$ Professor, Vidya Jyothi Institute of Technology, Aziznagar, Hyderabad
}

\begin{abstract}
Manufacturing of superior quality products at the reduced machining time increases the complexity in machining operation and warrants operator training in specific functional areas which augments the cost. In the current paper, an attempt is made to impregnate the degree of gaming in helping the improvement of machining skills. Gamification enhances the levels of attention by learning through frequent failures and consequently helps in incremental learning. The amalgamation of game mechanics and dynamics in non-gaming applications is a theme of interest in various fields such as education, handling sophisticated equipment, health care, and armed forces etc., in the last few years. The role of the academia is to develop new methodologies and tools which include digital games along with their gamification techniques in the contemporary learning practices. Furthermore, game techniques, gamification practices in education and e-learning are given special emphasis. A special discussion on engineering games, gamification platforms and empirical surveys is presented with a focus on education sector.
\end{abstract}

Keywords: Gamification, serious games, education, training, manufacturing

\subsection{Introduction}

Gamification is a term used to describe the application of video game mechanics to non-game processes to improve user engagement. Of late game based learning is increasingly being used in educational settings and is widely predicted to become mainstream in the future owing to its inherent advantages. Game based learning has been touted as a method that not only engages students but also motivates them. Game based learning has existed since long dating back to the roman times in learning the method of war.

\subsection{Game Mechanics}

Teachers create various educational exercises and monitor their students' responses and progress in real time. The exercises are presented in the form of short quizzes that include multiple choice, true/false and short answer responses with the option of including pictures in questions, so that diagrams, charts and any other item presented as an image can be incorporated into the question. In general, investigators conclude that gamification has a positive effect in engineering education by making difficult subjects more manageable, increase intrinsic motivation, scientific knowledge, collaboration, interest and reduce or better manage work load. Although gamification is still in its first steps, it has grown a momentum that will yield many research results in the near future, especially in the field of engineering education. Game mechanics entails with a guided norms for desired outcome. The objective of a teacher is to make the interactions of Game mechanics with the students highly affordable. It shall result in achievement, challenge and discovery on the part of learner which is more popularly termed as Game aesthetics.

\subsection{Game Based Learning}

Game based learning is made possible through computer simulations, animated processes, recorded live videos and step-by-step dialog boxes on various functional areas. Various games in practice include virtual training studio (Figure 1), Monkey wrench conspiracy project, PTC Mankin Extension, WeldSoft, animated assemblies (Figure 2) etc. are more popular in the engineering applications $[1,2]$.

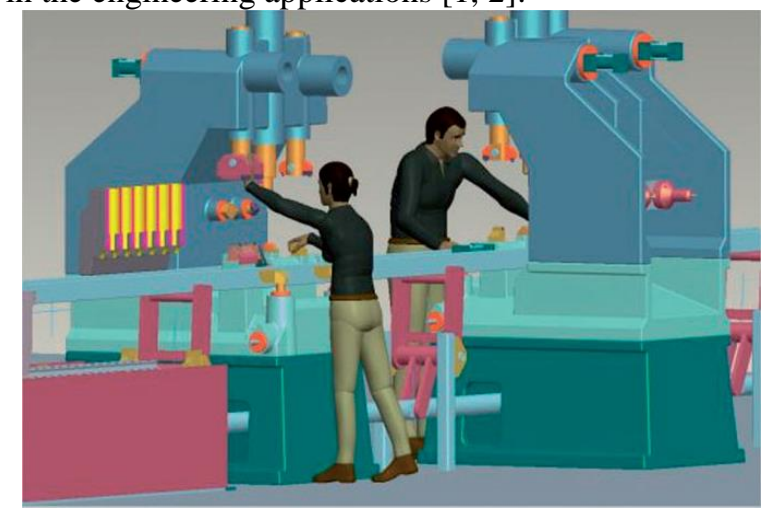

Figure 1: Virtual Training Studio 


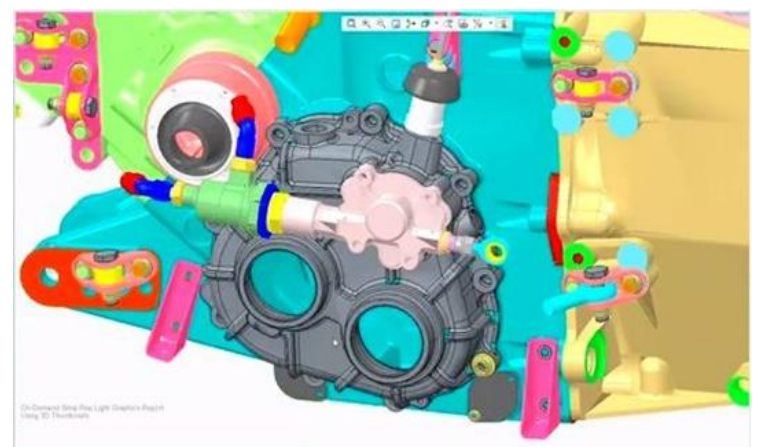

Figure 2: Animated Assembly

Institutional infrastructure is availed in the creation of games and simulations by the faculty with a view to make the students learn through the virtual course content (Figure 3).

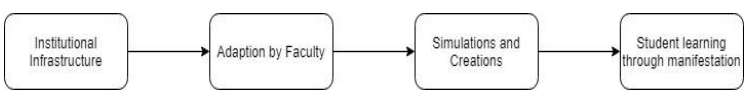

Figure 3: Game Based Learning Process Flow

These gamification techniques allow the students to initialize and get acquainted with the systems at higher learning rates. Further, in the manufacturing sector the operator can have a clearer idea of the operations already performed and the operations that are scheduled. These features can aid in visualizing important coherences and processes of everyday work. A status bar or a tachometer can communicate immediately the status of the current activity in terms of daily goal. Furthermore, important information for an operator is, that describes malfunctions or mistakes quickly, accurately and also informed on which specific step caused the problem and where it is located in the whole process. It could be crucial to provide the operator with as much detail as possible and also a tentative approach for a solution. e-learning is today the most innovative and modern educational process available [3, 4]. Its rapid growth is driven by the obvious benefits it entails. Participants of the elearning course can benefit at anytime, with concern to their own schedule availability and from anywhere, provided that they have access to a form of personal computer. It has a reduced cost in comparison to regular classroom learning and it is faster to deliver. Furthermore, e-learning gives the student the opportunity to pace and calibrate his or her own learning rhythm according to his or her own needs and capabilities $[5,6]$.

\subsection{Learning Analytics}

The learning analytics provide the opportunity to assess the magnitude of learning and monitors the progress at micro level of each of the students under consideration (Figure 4). In conventional non-gaming method, the learning time is evaluated from the time of making the first component and the learning rate. With the advent of game based learning, the number of clicks made on each of the learning features is reported back and the learning rate is evaluated [7, 8]. Also, it has the additional feature of zero defects in the fictitious manufacturing and the elimination of machine misuse which otherwise would have increased the cost [9].

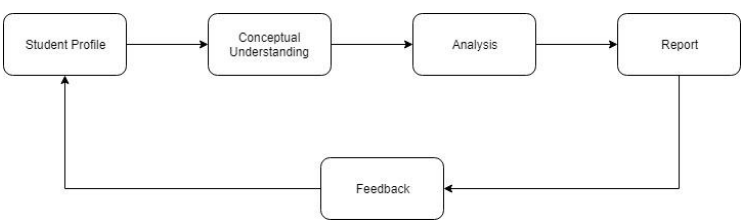

Figure 4: Learning Analytics

\subsection{Experimentation on Gamification}

The introduction to CNC machines and their working has been in the non-gamified environment and the consequent learning time is found to be high with more errors and defects in the component manufacture. The gaming version of the content is taken up for the study. It is a virtual machine and the demonstration on it is being taken up to all the concerned students. The method has psychologically given high boost among the learners and paved the way for reduction of fear among the learners sine it will not cause any catastrophe during the mischievous handling of the virtual machine (Figure 5).

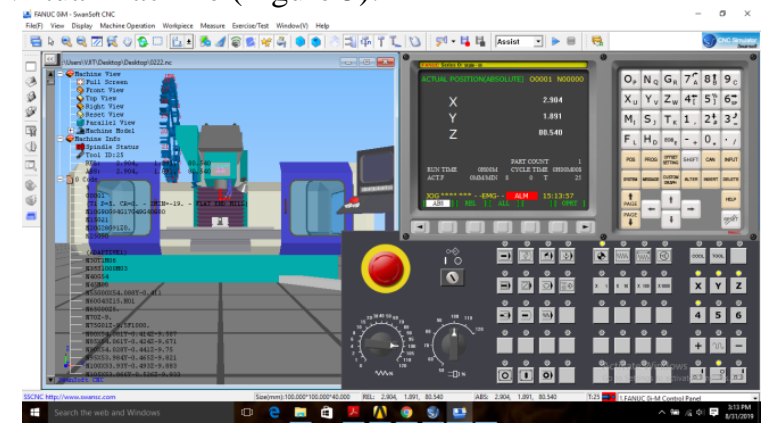

Figure 5: Virtual CNC machine

With a view to assess the learnability, two groups of thirty students each are undertaken. One of the groups is deployed on CNC conventional machine while the other group is on the virtual machine. The students who are deployed on conventional machine are named as group ' $\mathrm{A}$ ' while the others on the virtual machine are named as group ' $\mathrm{B}$ '. The students are asked to perform a turning operation on these machines. The time of performing the activity by each of the student groups is recorded.

\subsection{Results \& Discussion}

The time to perform the turning operation by each of the students in the group ' $\mathrm{A}$ ' working on conventional $\mathrm{CNC}$ lathe is recorded. Due to their inherent variation in their learning capability, the time of performing the activity is different from each other. The sample 
means and variance of both the groups are computed. The average time is computed and is found to be 75 minutes for the group ' $A$ '. The time included in it comprising of the activities namely part programming, coolant checking, loading of raw material, tool selection, machining and unloading of finished product. The other group ' $\mathrm{B}$ ' has worked with gaming principle on virtual machine. The average time of doing the same activity by this group is recorded and found to be 62 minutes. Employing the principles of testing of hypothesis, a two tail test is conducted for equality of the means at $95 \%$ confidence level and $5 \%$ level of significance with a null hypothesis of equality of both the means [10]. The normal test statistic ' $z \geq$ 1.96 ' implied that the rejection of null hypothesis. The learning of each feature of the virtual machine is reported as feedback is made known to students as a game based learning technique. This kind of learning analytics allowed them to grasp the key aspects of virtual $\mathrm{CNC}$ machine easily and consequently helped in reducing the learning time. Thus the group is having lower average time which enabled quick learning. Apart from the advantage of reducing the learning time with gaming method of learning system, it has a psychological impact on the minds of students which helped in instilling the confidence of working with modern equipment possessing high complexities.

\section{Conclusions}

- $\quad$ Statistics on games and gamification process are presented in order to exhibit the importance of digital games in everyday life in all fields especially in engineering education.

- Gamification has a positive effect in engineering education by making difficult subjects more manageable, increase intrinsic motivation, scientific knowledge, collaboration, interest and reduce or better manage work load.

\section{Acknowledgements}

The authors are grateful to Dr. A. Padmaja, Principal, Vidya Jyothi Institute of Technology, for the support and encouragement extended while authoring the current research paper.

\section{References}

[1] Prensky, M. Information and Background on The Monkey Wrench Conspiracy, http://www.marcprensky.com/ Last accessed $08 / 2015$.

[2] Kosmadoudi, Z., Lim, T., Ritchie, J., Louchart, S., Liu, Y., Sung, R.: Eng. design using game-enhanced CAD: Potential to augment user experience with game elements. CAD 45 (3) (2013) 777-795.

[3] Aziz, E.-S., Esche, S. K. \& Chassapis, C.: Review of the state of the art in virtual learning environments. Computers in Education Journal, Vol. 20, No. 1, pp. 22-35, 2010.

[4] Killi. K., Digital Game Based Learning towards an experimental gaming model, The Internet and Higher Education, Volume 8, Issue 1, pp. 13 - 24, 2005.

[5] Pivec M.M, Play and Learning, Potentials of Game Based Learning, British Journal of Educational Technology, Volume 38, Issue 3, pp. $387-393,2007$.

[6] Tobias. S, Flether D J and Wind A, Game Based Learning, Handbook of research on Educational communication and Technology, $4^{\text {th }}$ edition, Springer, 2014.

[7] Collar B, Shernoff D, Video Game Based Education in Mechanical Engineering, International Journal of Engineering Education, Volume 25, Issue 2, pp. $308-$ 317, 2009.

[8] H J Park and J H Bae, Analysis and Survey of Gamification, Advanced Science and Technology Letters, Vol.39, pp.24 - 27, 2013.

[9] C Cheong, F Cheong and J Filippow, Quick Quiz: A Gamified Approach for Enhancing Learning, PACIS 2013 Proceedings, Pacific Asia Conference on Information Systems, 2013.

[10] Robert A Donnely, Business Statistics, $2^{\text {nd }}$ edition, ISBN 13: 978-0321925121 